\title{
Bimetallic Cu-Ni nanoparticles supported on activated carbon for catalytic oxidation of benzyl alcohol
}

\author{
Melody Kimi ${ }^{\text {a,*, }}$ Mohd Muazmil Hadi Jaidie ${ }^{\mathrm{b}}$, Suh Cem Pang ${ }^{\mathrm{b}}$ \\ ${ }^{a}$ Centre for Pre-University Studies, Universiti Malaysia Sarawak, 94300 Kota Samarahan, Sarawak, Malaysia \\ ${ }^{\mathrm{b}}$ Department of Chemistry, Faculty of Resource Science and Technology, Universiti Malaysia Sarawak, 94300 Kota Samarahan, Sarawak, Malaysia
}

\section{A R T I C L E I N F O}

\section{Keywords:}

Bimetallic catalyst

$\mathrm{Cu}-\mathrm{Ni}$

Benzyl alcohol oxidation

\begin{abstract}
A B S T R A C T
A series of bimetallic copper-nickel $\left(\mathrm{CuNi}_{\mathrm{x}}, \mathrm{x}=0.1,0.2,0.5\right.$ and 1$)$ nanoparticles supported on activated carbon (AC) were prepared by deposition-precipitation method for the oxidation of benzyl alcohol to benzaldehyde using hydrogen peroxide as oxidising agent. Analyses by means of X-ray Diffraction (XRD) and Scanning Electron Microscopy (SEM) confirmed that $\mathrm{Cu}$ and $\mathrm{Ni}$ was successfully added on the surface of activated carbon. $\mathrm{CuNi} \mathrm{N}_{1} / \mathrm{AC}$ showed the best catalytic activity for the oxidation of benzyl alcohols to the corresponding aldehyde within a short reaction period at $80{ }^{\circ} \mathrm{C}$. The catalytic performance is significantly enhanced by the addition of equal amount of $\mathrm{Ni}$ as compared to the monometallic counterpart. This result indicates the synergistic effect between Ni and $\mathrm{Cu}$ particles in the catalytic oxidation reaction.
\end{abstract}

\section{Introduction}

The oxidation of benzyl alcohol to benzaldehyde is one of the most essential functional group transformations. Benzaldehyde is commonly used as a starting material in the preparation of perfumery and pharmaceutical $[1,2]$. The usage of conventional routes to produce benzaldehyde involves the release of pollutants, thus direct oxidation of liquid benzyl alcohol is widely investigated [3-5]. Therefore, the development of effective and efficient catalysts for this approach utilizing mild reaction conditions at low reaction temperature is been done [3-5].

Noble metals such as Au [6,7] and Pd [8] have shown their potentials to fulfil this requirement. However, these catalysts are expensive thus hinders wide application. Recently, focus has been made on the usage of transition metals as catalyst [9-15]. It has been reported that $\mathrm{Cu}$ [9] and Ni $[10,11]$ catalyst both has high conversion towards the oxidation of benzyl alcohol to benzaldehyde. Ni is usually added as the second metal for the oxidation of benzyl alcohol as reported for $\mathrm{Mn} / \mathrm{Ni}$ [12] and $\mathrm{Ni} / \mathrm{Mg}$ [13]. The role of Ni was found to provide sites for oxygen activation [12]. Bimetallic Cu-Mn [14], Cu-Au [15] have showed superior catalytic performance in the oxidation of benzyl alcohol to benzaldehyde compared to those of their monometallic counterparts because of their tunable and synergistic effect. Therefore, we aim to investigate the role of $\mathrm{Ni}$ incorporated into $\mathrm{Cu}$ lattice which might change the physicochemical properties of bimetallic catalyst.
Catalytic properties are also strongly dependent on their composition, size and interaction with support. Herein, activated carbon was used as the catalyst support due to its advantageous features such as large surface area [16] and good chemical stability [17]. Activated carbon also plays a role in maintaining the catalytic active phase in a highly dispersed state [18]. In this study, a series of bimetallic $\mathrm{CuNi}_{\mathrm{x}}(\mathrm{x}=0.1,0.2,0.5$ and 1) nanoparticles supported on activated carbon was prepared using deposition-precipitation method to evaluate the effect of different ratios of $\mathrm{Ni}$ added into $\mathrm{Cu}$ catalyst. The comparison between monometallic $\mathrm{Cu}$ and $\mathrm{Ni}$ nanoparticles and bimetallic $\mathrm{Cu}-\mathrm{Ni}$ nanoparticles were also done. The catalytic activity of these catalysts was evaluated for the oxidation of benzyl alcohol to benzaldehyde using hydrogen peroxide as an oxidant. The results show that the addition of $\mathrm{Ni}$ at optimum amount to $\mathrm{Cu}$ catalyst demonstrates the dual role of $\mathrm{Cu}$ and $\mathrm{Ni}$ towards the catalytic activity of aerobic benzyl alcohol oxidation reaction.

\section{Experimental}

\subsection{Preparation of catalysts}

The $\mathrm{CuNi}_{\mathrm{x}} / \mathrm{AC}(\mathrm{x}=0.1,0.2,0.5,1)$ nanoparticles catalyst were prepared by using homogeneous deposition-precipitation method previously reported with slight modification [19]. In brief, for the synthesis of $\mathrm{CuNi}_{0.1} / \mathrm{AC}$ catalyst, $1.0 \mathrm{~g}$ of AC was added into $50 \mathrm{~mL}$ aqueous solution

\footnotetext{
* Corresponding author.

E-mail address: kmelody@unimas.my (M. Kimi).
} 